\title{
The Relationship Between Multiple Intelligences, Culture And Diversity
}

Stefanie Denise Wilson, (E-mail: sdwilson@hawaii.edu), University of Hawaii

Bahaudin G. Mujtaba, (E-mail: mujtaba@nova.edu), Nova Southeastern University

\begin{abstract}
The topic of intelligence, whether hereditary or acquired, has been the subject of discussion since the beginning of time and will probably keep researchers and authors talking for many years to come. However, one statement needs to be clarified that studies seem to indicate that people of all backgrounds and cultures have similar capacities of intelligences. Despite this fact, there seems to be widespread discrimination and stereotypes in today's workplace. Effective management and leadership require that our workplaces are free of biases so everyone can work synergistically. The paper provides some reflections on multiple intelligences, culture and diversity management and concludes by offering a discussion of social and emotional intelligences for diversity management as well as suggestions for tolerating, respecting and understanding each other's differences.
\end{abstract}

\section{INTRODUCTION}

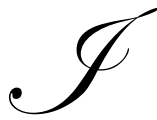

n 1983 and after extensive research, Gardner published his book Frames of Mind with its radically new conception of intelligences. Previous views of intelligence had entailed a single, yet multi-faceted, factor of intelligence labeled "g." Also, the claim that some individual possessed more intelligence than others was an accepted fact. Moreover, intelligences was viewed as stable, capable of being measured even early in life (Gardner, 1983).

In contrast to the prevailing view, Gardner (1999) suggested the existence of multiple intelligences, each of unique yet equal significance, present in every normal individual. Strengthening one's intelligence, he claimed, was the whole purpose of education. Gardner situated intelligences in culture and in context, which proved them useful, he argued against the appropriateness of pencil and paper tests for assessing intelligence. Although these tests conceivably measure "g," Gardner challenged their validity as predictors' of the ability to solve problems and succeed in real-world situations. For Gardner, this concept of intelligence seemed to pass by many strikingly talented individuals, and a focus on "g" appeared biased and clearly unproductive.

Psychologist, author, and Professor of Neurology at Boston University's Medical School and Professor of Education at Harvard's Graduate School, Howard Gardner is considered a pioneer for exploring the sources of evidence regarding a list of human intelligences known as Multiple Intelligences (MI) theory (Oregonian Publishing Company, 1999). "Gardner wrote about his observations of multiple intelligences in what has turned out to be a seminal book in the educational community, Frames of Mind, which was published in 1983" (Project Summit, 2002, p. 1). Gardner sought to expand the concept of intelligence (Kincheloe et al., 1999). "Gardner believed that the primary measurement of intelligence (e.g. IQ tests) was too narrow and limiting, and proposed his theory of multiple intelligences" (Johnson \& White, 2002, p. 2). Gardner linked an individual's potential for processing information with culturally valued capabilities (Sternberg et al., 2003). "Almost eighty years after the first intelligence tests were developed, Gardner challenged the notion that intelligence is something that can be objectively measured and reduced to a single quotient or score" (Stanford, 2003, p. 80). Gardner's decades of research signified progress in cognitive and educational psychology (Kincheloe et al., 1999). Gardner's studies "[challenged] the widespread belief held by many psychologists and entrenched in many languages that intelligence is a single faculty and that one is either smart or stupid across the board" (Gardner, 1999, p. 34). Gardner's theory of multiple intelligences proposed a new theoretical framework for thinking about human intelligences (Kincheloe et al.). "MI theory endorses three key components: (a) 
we are not all the same; (b) we do not all have the same kind of minds; and (c) education works most effectively if these differences are taken into account rather than denied or ignored" (Gardner, p. 91).

Gardner's theory of multiple intelligences approach is a radical departure from the psychometric testing approach. Unlike the "psychometric approach to intellectual plurality, which was, and still is generally restricted to those faculties accessible through brief oral questions or paper-and-pencil instruments," Gardner's approach is quite different (Gardner, 1999, p. 35). The theory of multiple intelligences was created with the end in mind, by focusing on the problems that humans solve and linking those to the intelligences responsible (Gardner, 1993). "[Gardner] has approached the subject of intelligence from an entirely different angle, one that combines scientific research and speculation with personal experience" (The New Republic, 1998, p. 20). Gardner produced data from various sources. "MI theory is based on empirical evidence, in fact hundreds of studies where actual intelligences were identified and delineated on the basis of brain science, psychology, anthropology, and other relevant disciplines" (Gardner, 1999, p. 85). Gardner's theory of multiple intelligences, unlike psychometric theories, is grounded in empirical research. "Instead of relying primarily on the results of psychometric instruments, [Gardner] laid out a set of eight separate criteria and combed the relevant scientific literature for evidence on the many candidate faculties" (Gardner, 1999, p. 35). Like Galton and Binet, Gardner's research approach began with sensory modalities and resulted in diverse research findings on the faculties of various candidates (Gardner, 1999). "Gardner accepted the available evidence, and if the candidate faculty met the set of criteria reasonably well Gardner called it a human intelligence" (Gardner, p. $35)$.

\section{INTELLIGENCE: GARDENER'S CRITERIA}

Gardner's definition purposely includes a reference to cultural context of the individual. Gardner (1983) noted that certain capacities might be highly developed in an individual, but if they are not highly valued in one or more cultures, they cannot be considered intelligences. Example would include "keen gustatory or olfactory senses," or the ability to recognize faces. He does recognize the variability in the kinds of things valued among differing cultures, which explains why the definition includes one or more cultures. Gardner discusses the importance of making products as a sign of intelligence, something not always included in discussions of intelligence. Given the importance of products of many cultures, the presence of both in definitions is not surprising. Gardner introduced criteria by grouping them from disciplinary roots, such as biological sciences, logical analysis, developmental psychology, and traditional psychology (Gardner, 1999; Smith, 2002).

Gardner (1999) stated that certainly the aforementioned criteria of human intelligence are by no means the final word on the identification of intelligence. Gardner asserted, "today [he] might define them differently, and would stress much more the relevance of cross-cultural evidence. Still, taken together, they constitute a reasonable set of factors to be considered in the study of human cognition" (p. 41).

\section{Gardner's Multiple Intelligences}

Gardner's original list of multiple intelligences includes an existence of seven human intelligences. "Although the intelligences are anatomically separated from each other, Gardner claims that the seven intelligences very rarely operate independently. Rather, the intelligences are used concurrently and typically complement each other as individuals develop skills or solve problems" (Brualdi, 1996, p. 61).

Linguistic and logical-mathematical intelligences are two of the seven original domains of multiple intelligences posed by Gardner (Sternberg, 2003). Gardner (1999) asserted "linguistic and logical-mathematical intelligences have typically been valued in school. Linguistic intelligence involves sensitivity to spoken and written language, the ability to learn languages, and the capacity to use language to accomplish certain goals" (p. 41). High linguistic intelligence is demonstrated among individuals such as lawyers, speakers, and writers. "Mathematicians, logicians, and scientists exploit logical-mathematical intelligence, involving the capacity to analyze problems logically, carry out mathematical operations, and investigate issues scientifically" (Gardner, 1999, p. 42). Certainly, a blend of both linguistic and logical-mathematical intelligence is indeed quite helpful for those students who continuously take tests. "The fact that most psychologists and most other academics exhibit a reasonable amalgam of linguistic and 
logical intelligence made it almost inevitable that those faculties would dominate tests of intelligence" (Gardner, p. 42).

Gardner (1999) noted three additional intelligences that are essentially highly regarded in the arts and other areas, namely, musical intelligence, bodily-kinesthetic intelligence, and spatial intelligence. "Musical intelligence entails skills in the performance, composition, and appreciation of musical patterns" (Gardner, p. 42). Musical intelligence is embodied by persons such as musical composers, musical directors, or singers. Gardner said, bodily-kinesthetic intelligence "entails using one's whole body or parts of the body to solve problems or fashion products. Dancers, actors, or athletes display bodily-kinesthetic intelligence. This form of intelligence is also important for craftspersons, surgeons, mechanics and other technically oriented professionals" (p. 42).

Spatial intelligence is generally demonstrated by individuals such as architects, graphic writers, or chess players (Gardner, 1999). Gardner postulated, "spatial intelligence features the potential to recognize and manipulate the patterns of wide space; those used for instance, by navigators and pilots as well as patterns of more confined areas such as those of importance to sculptors or surgeons" (Gardner, p. 42).

Gardner's (1999) original list of seven multiple intelligences include the final two intelligences, which he defined as personal intelligences. Gardner's two personal intelligences include interpersonal intelligence and intrapersonal intelligence. Interpersonal intelligence "denotes a person's capacity to understand the intentions, motivations, and desires of other people, and consequently, to work effectively with others. Salespeople, teachers, clinicians, religious leaders, political leaders, and actors all need acute interpersonal intelligence" (Gardner, p. 43). Intrapersonal intelligence has a different focus than interpersonal intelligence. Intrapersonal intelligence "involves the capacity to understand oneself, to have an effective working model of oneself including one's own desires, fears, and capacities and to use such information effectively in regulating one's own life" (Gardner, p. 43).

\section{Gardner's Additional Multiple Intelligences Considered}

After publishing Frames of Mind, Gardner was asked to explain the work of great biologists who exhibited an unusual ability to recognize natural patterns and classify objects. Realizing that the original seven intelligences could offer no such explanation, Gardner began to examine this ability against his criteria and eventually considered as an addition to his list naturalist intelligence. This capacity allows individuals to discriminate among plants and animals, as well as other natural features, such as rock formations, or clouds. Gardner speculates that much of consumer society, which distinguishes between everything from cars to sneakers, exploits this intelligence. Typical end-states include biologist and botanist.

Spiritual intelligence is indeed a rather complex human intelligence. Gardner (1999) said, "The realm of the naturalistic seems straightforward in comparison to spiritual intelligence" (p. 53). Gardner proposed three distinct senses of spirituality; spiritual as achievement of a state of being, spiritual as effect on others, and spiritual as concern with cosmic or existential issues.

"When it comes to the spiritual realm, however, the two forms of knowing must be more carefully distinguished. The first sense of spiritual delineates the realms of experience or domains of existence that people seek to understand" (Gardner, p. 55). There are those who are recognized as being more skilled at meditating, being in touch with psychic, spiritual experiences, and achieving psychological states (Gardner). "One may achieve a state of spirituality by following a traditional route (e.g. exercising suggestions by a priest) a personalized form of control of consciousness (e.g. hallucinogenic drugs) or sensory experiences such as listening to music" (p. 56). In short, Gardner suggests that there are different ways of achieving a state of spirituality or knowing. "These two forms of knowing, mastering a set of contents and mastering the craft of altering one's consciousness can be seen as uses of the mind, whether one considers such uses profound or frivolous, inspired or misguided" (Gardner, p. 57). Certainly one can be affected by another's spirituality. Gardner (1999) believed, "certain people may be considered spiritual because of the effects they apparently exert on others, either through their activities or, perhaps even more, through their sheer being" (p. 57). Gardner suggests there are three distinct senses of the spiritual. It is possible to arouse all three senses of the spiritual. The distinct senses of the spiritual are one's ability to "know about experiences and cosmic entities not 
apprehended in a material sense, to relate to the supernatural world, and to understand the ultimate questions, mysteries and meaning of life" (p. 54).

Although the content of spiritual knowledge may seem straightforward, in practice the concept is quite controversial (Gardner, 1999). "Having read numerous accounts of the spiritual realm, [Gardner concluded that] it refers to everything: mind, body, self, nature, the supernatural, and sometimes even to nothing" (Gardner, p. 55). Gardner said that spirituality is contagious, and is typically passed on from one spiritual person to another.

Gardner (1999) said spiritual or religious intelligence is considered a part of existential intelligence. Gardner postulated, "Existential intelligence or a concern with the ultimate issues seems the most unambiguously cognitive strand of the spiritual. That is because it does not include features that, according to my definition, are not germane to a consideration of intelligence" (p. 60). Gardner mentioned core characteristics of persons with existential intelligence. Gardner proposed "a core ability for a candidate existential intelligence: the capacity to locate oneself with respect to the further reaches of the cosmos, the infinite and infinitesimal, and the related capacity to locate oneself with respect to such existential features" (p. 60). Gardner mentioned several existential features of the human condition that are demonstrated by candidates of existential intelligence. The existential features of the human condition noted by Gardner include "the significance of life, the meaning of death, the ultimate fate of the physical and the psychological worlds, and profound experiences as love of another person or total immersion in a work of art" (Gardner, p. 60).

\section{Multiple Intelligence Myths And Realities}

Gardner (1999) discussed in his book Intelligence Reframed several myths and realities regarding multiple intelligence and the wide spread interpretations of the theory. When asked, should researchers "create a variety of tests and secure the associated scores?" Gardner responded, "my concept of intelligences is an outgrowth of accumulating knowledge about the human brain and about human cultures, not the result of a priori definitions or factor analyses of a set of test scores" (p. 80). Thus, Gardner (1999) believed that human intelligences should be assessed in an intelligent and fair way. Gardner asserted, "I would like to get rid of intelligence and aptitude tests; they measure only two forms of intelligence and have destructive social effects" (U.S. News and World Report, 1984). In short, Gardner opposed developing tests to measure intelligences. He believed "It goes against the grain of [MI philosophy] to develop tests to measure intelligences" (Collins, 1998, p. 62).

In his book, Gardner was questioned, "If MI theory is incompatible with $\mathrm{g}$ (the term used by psychometricians to designate the existence of general intelligence) with heriditarian accounts, and/or with environmental accounts of the nature and causes of intelligence?" (p. 87). Gardner (1999) replied that, "MI theory questions not the existence but the province and explanatory power of g. MI theory is neutral on the question of the heritability of specific intelligences, instead of underscoring the centrality of genetic and environmental interactions" (p. 87).

Gardner (1999) received other inquiries regarding the theory of multiple intelligences. A comment pertaining to "the broadening of the term intelligence to include a broad spectrum of psychological constructs, and MI rendering the terms and its typical connotations useless" was also a myth addressed by Gardner (Gardner, p. 88). Gardner stated that "the standard definition of intelligence narrowly constricts our view by treating a certain form of scholastic performance as if it encompassed the range of human capacities and by engendering disdain for those who happen not to score well on a particular psychometric instrument" (p. 88).

\section{The Bell Curve}

In 1994, the publication of the Bell Curve generated an uproar and much controversy from numerous academic circles and communities (Samuda, 1998). Herrnstein and Murray's book, The Bell Curve: Intelligence and Class Structure in American Life attempted to uphold their hypothesis on group differences in intelligence (Graves, 2002; Samuda, 1998). "The arguments presented in The Bell Curve were not, for the most part original. The origin of the author's ideas was in the work of Galton, the British naturalist and mathematician who introduced the term eugenics to the vocabulary of science" (Welch, 2002, p. 181). The Bell Curve essentially supported eugenics, the idea 
of enhancing the human species by controlling heredity. According to Graves (2002), The Bell Curve also consisted of the following elements:

1. General intelligence can be quantified by a single metric known as g.

2. Standardized tests can be utilized to measure g.

3. $\quad \mathrm{g}$ is mostly genetically determined.

4. Races differ consistently in their performance on intelligence tests.

5. This difference must in part be due to the genetic differences between races.

6. Races of human being can be unambiguously defined by biological means (p. 58).

Hernstein and Murray suggested two premises in The Bell Curve: "First, measured intelligence (IQ) is largely genetically inherited, and second, IQ is correlated positively with a variety of measures of socioeconomic success in society that are inversely correlated with criminality and other social failures" (Welch, 2002, p. 177). In short, Hernstein and Murray argue that intelligence is hereditary, and those of higher intelligence should be served by those of lower intelligence (Samuda, 1998). The "take home" message of Hernstein and Murray's The Bell Curve is that environmental interventions such as Head Start programs and affirmative action will not change the social divide because innate genetic differences in racial intelligence will always intervene (Graves, 2002). The authors also believed that "a low IQ in the U.S. meritocracy is a strong predictor of crime, poverty, and unemployment, they argue, and a high IQ increasingly is a ticket to wealth and a stable marriage" (U.S. News and World Report, 1994, p. 73).

The recommendations from academic circles and the community in response to The Bell Curve centered on the Hernstein and Murray's lack of analysis of the data and solidifying scientific grounds. Neisser et al. [as cited in Sternberg \& Kaufman, 1998] said that "among psychologists there seemed to be fairly widespread agreement that the social-policy recommendations of Herrnstein and Murray which call for greater isolation of and paternalism toward those with lower IQs do not follow from their data" (p. 491). Although other responses from scholars and researchers were largely political or emotional in character, they attacked the book on scientific grounds (Sternberg \& Kaufman). Graves (2002) argued, "The Bell Curve does not, however, advance any specific evolutionary genetic rationale for how racial differences in genes related to the intelligence phenotypes they report originate" (p. 58).

The idea that human species has no races in the biological sense is not a recent phenomena in anthropology (Fish, 2002). 'Psychologists' and other social scientists' lack of awareness of the basics of physical anthropology is illustrated by The Bell Curve's evaluation of the scientific status of the work of the developmental psychologist J. Phillippe Rushton" (Fish, p. 3). Rushton attempts to define what races are and classify people into biological races that are scientifically inaccurate. Rushton [as cited in Fish] "assumed the existence of Mongoloids, Caucasoids, and Negroids as biological entities; blithely lumped together widely varying groups of individuals and data of uneven quality into three categories; and referred to resulting numbers as racial differences" (p. 5). Furthermore, Rushton labels and categorizes Negroids, Mongoloids, and Caucasoids based on biological differences. "Rushton actually asserts that Negroids have small brains, large genitals, and lots of sex; that Mongoloids have large brains, small genitals, and little sex; and that Caucasoids fall in between" (Fish, p. 3). It is believed that perhaps the publication of The Bell Curve failed miserably with its lack of analysis of pertinent data based on scientific grounds and served to foster the dialogue among scientists' views about race and eugenics that have remained dormant since the end of World War II (Fish, 2002).

\section{Broad Theories Of Intelligence}

For decades, analytic intelligence (IQ) comes to mind when individuals think about intelligences. Lately, however, a number of additional theories of intelligences have been proposed. These additional theories of intelligences may offer helpful interpretations or suggestions for leadership successes or failures beyond our comprehension based on traditional IQ (Blackburn, 2002).

The task of rethinking intelligence has surged with the changes of social theory and critical pedagogies (Kincheloe et al., 1999). "Whereas intelligence was once presumed to compromise a single factor, more recently psychologists have suggested that intelligence is multi-factorial, that there exist a number of independent facets to 
intelligence" (Morand, 2001, p. 22). Furthermore, it is believed that not only is intelligence demonstrated in various ways, it is also learnable (Kincheloe et al., 1999). "These multiple forms of intelligences are not only [learnable] and possessed by effective leaders, but they are the types of characteristics that may make leaders effective in a range of leadership situations" (Riggio et al., 2002, p. 3). One of these is Howard Gardner's (1983, 1999) Theory of Multiple Intelligences. Another is Emotional Intelligence by David Goleman (1998). In addition to theories of multiple intelligences, emotional intelligence and successful intelligence, "social intelligence, practical intelligence are other facets of the broader construct of intelligences that are implicated in good leadership" (Riggio et al., p. 3).

\section{Successful Intelligence}

Successful intelligence is also known as the triarchic theory (Sternberg et al., 2000). "Successful intelligence is the ability to achieve success by one's own standard's given one's sociocultural context. There is no single criterion of success that serves as a standard for all people. Rather, people define their own criteria of success" (Riggio et al., 2002, p. 10). It is through mental mechanisms, experience, and the use of cognitive mechanisms that successful intelligence occurs (Sternberg et al., 2000). Sternberg defined "successful intelligence as a fusion of traditional notions of analytical intelligence and practical intelligence" (p. 3). Although there is no single criterion for success, and it is defined by each individual, people's success is predicated on their ability to capitalize on their strengths and compensate for their weaknesses (Sternberg et al., 2000) "People find their own idiographic patterns of strengths and weaknesses, and develop patterns of capitalization, correction, and compensation that enable them to achieve their goals or not" (Riggio et al., p. 10).

Successful intelligence means more than just merely adapting to one's environment (Riggio et al., 2002). "Successful intelligence involves adapting to environments while balancing among adaptation to environments, shaping of environments, and selection of environments. Adaptation involves changing oneself to suit the environment; shaping involves changing the environment, and selection involves finding a new environment" (Riggio et al., p. 10).

Leadership is primarily a shaping function and requires in many instances a blending of both adaptation with shaping (Riggio et al., 2002). "Thus while conventional intelligence emphasizes adaptation, successful intelligence as applied to leadership emphasizes shaping" (Riggio et al., p. 10). Successful intelligence emphasizes establishing a set of rules to guide others and less of figuring out how to succeed within a set of rules (Riggio et al.).

\section{Practical And Social Intelligence}

Practical intelligence is commonly known as common sense (Sternberg, et al., 2003). "Practical intelligence is that aspect of successful intelligence that is relevant to adaptation, shaping, and selection in everyday life" (Riggio et al., 2002, p. 11). There are several ways of measuring practical intelligence. "One of the ways to measure practical intelligence involves the measurement of tacit knowledge. Tacit knowledge refers to what one needs to know to succeed in a given environment, and is knowledge that is not explicitly taught or verbalized" (Riggio et al., p. 11). There are several main characteristic of tacit knowledge. Riggio et al., (2002) mentioned several of the main characteristics of tacit knowledge, which include the following:

1. Generally acquired on one's own

2. Usually unspoken and often implicit

3. $\quad$ Procedural in nature

4. Not readily articulated

5. Directly related to practical goals that people value. (p.11).

Riggio et al. (2002) suggested demonstrating practical intelligence by only using tacit knowledge is not sufficient for effective leadership; however, it is an important aspect of leadership effectiveness. "Instead of workers with high IQ scores, the workplace may need workers with tacit or practical intelligence skills. Moreover, tacit intelligence is inclined to be more closely related to particular situations and experience than IQ"(Stamps, 1996. p. 44). Perhaps the use of tacit knowledge by workers may provide for a greater understanding of intelligent behavior in real world settings, as well as foretell success in such settings (Sternberg et al., 2000). 
Social intelligence was introduced by Thorndike, who defined it as the ability to understand others and demonstrate good judgment or get along in relation to others (Sternberg et al., 2000). "What sets apart the newer conceptualizations of intelligence from the older intelligence as a stable trait approaches is the view of intelligence as a process of adaptation" (Riggio et al., 2002, p. 148). Studies indicate that there is a multidimensional aspect of social intelligence that includes understanding and dealing with people coupled with social adaptability (Sternberg et al.). "Cognitive skills and knowledge interact with environmental demands in a mutual shaping that enhances the adaptive fit of the individual to the environment" (Riggio, et al., p. 149). The intelligent person handles this situation accordingly. "The intelligent person musters current knowledge and ability to relate to the problem environment in a flexible way that allows for the acquisition of new skills and knowledge helping individuals to develop solutions necessary for goal attainment" (Riggio et al., p. 149).

The socially intelligent person is believed to have a generous degree of cognitive abilities such as openness with others, and behavioral elements such as interpersonal warmth (Sternberg et al., 2003). "The socially intelligent person is adept at reading the characteristics of the situation for cues and clues that define the nature of the interpersonal context and the appropriate behaviors for the context" (Riggio et al., 2002, p. 150). The socially intelligent person demonstrates leadership effectiveness. "The effective leader knows when a situation requires formal authority and presentation or a more informal and intimate setting. Social knowledge is a requisite for appearing as a credible leadership figure" (Riggio et al., p. 150).

\section{Emotional Intelligence}

The history of emotional intelligence research has been a little over a decade and has invoked much interest on the topic (Sternberg et al., 2003). "The most recent explosion of interest in intelligence and leadership has been fueled by the success of Daniel Goleman's Emotional Intelligence" (Riggio et al., 2002, p. 3). In 1995, Goleman was instrumental in bringing popularity to the concept of emotional intelligence (Sternberg et al., 2000). Goleman, a psychologist, argued that factors other than IQ contribute greatly to success and happiness. Goleman said such factors include patience, persistence, and the ability to empathize with and respond well to the emotions of others" (Post Gazette Publishing Company, 1996, p. 2).

Salovey and Mayer coined the term emotional intelligence and introduced the ability and mixed models as views of emotional intelligence (Sternberg et al., 2000). "Emotional Intelligence (EI) evolved from works by such theorists as Gardner, Williams, and Sternberg who proposed broader approaches to understanding intelligence. Salovey and Mayer also included Gardner's intrapersonal and interpersonal components in the construct" (Tucker, Sojka \& Barone, 2000, p. 333).

Like other theorists, Goleman believed that IQ testing misses the mark in determining who will be successful in life (Sternberg et al., 2000). "The essence of Goleman's theory of emotional intelligence can be reduced to the following statement: Success results from an awareness of one's own emotional state and an awareness of another's emotional state that lead to productive action" (Kaschub, 2002, p. 10). Productive action is the ability to use emotions to reason and solve problems resulting from effectively implementing the emotional intelligence components. Riggio et al., (2002) cited the following components of emotional intelligence:

1. The ability to recognize your own emotions or your own feelings as they happen and handle these emotions,

2. The ability to engage in self-control to motivate oneself,

3. The ability to recognize the emotions of others,

4. The ability to handle relationships (p. 174).

Riggio [as cited in Goleman, 1998] discussed the Goleman's ideas on emotional intelligence that were expanded to include 25 competencies grouped into five basic categories, which include:

1. Self-Awareness: Emotional awareness, accurate self-assessment, and self-confidence,

2. Self-Regulation: Self-control, trustworthiness, conscientiousness, adaptability, and innovation,

3. Motivation: Achievement, commitment, initiative, and optimism, 
4. Empathy: Understanding of others, developing others, service orientation, diversity, and political awareness, 5. Social Skills: Influence, communication, conflict management, leadership, change catalyst, building bonds, collaboration/co-operation, and team capabilities (p. 60).

Leaders influence others to take action. "The most effective leaders are alike in one crucial way: they have a high degree of what has come to be known as emotional intelligence. Recent research clearly shows that emotional intelligence is the sine qua non of leadership" (Goleman, 1998, p. 92). Emotional intelligence skills can assist in various leadership functions. "Emotional intelligence can facilitate these [leadership] functions, but the successful leader will require more than just emotional intelligence to carry these out" (Riggio et al., 2002, p. 63). While being aware of one's emotions and the emotions of others certainly influences managerial performance, it is also necessary for effective leaders to use, understand, and manage emotions to achieve leadership success (Riggio, et al.).

Leaders should be in touch with their emotions and use their emotions to be effective. "Using emotions allows leaders to understand and motivate others by making emotions available, engage in multiple perspectives that can help planning, and engage in activities facilitated by emotions (e.g. detailed work when feeling neutral or down)" (Riggio et al., 2002, p. 64). It is paramount that effective leaders have the ability to understand emotions as well. "Understanding emotions includes the ability to recognize relationships between emotions, determine the meaning emotions convey, and recognize how emotions change from one state to another. Understanding emotions provides leaders with the information on what makes people tick" (Riggio et al., p. 64). While using and understanding emotions are important to leadership effectiveness, managing emotions is also a critical aspect of leadership effectiveness. Managing emotions allows leaders to handle the stress of organizational life and the multi-faceted opportunities it presents. Effective leaders demonstrate the ability to focus on the effective coping strategies versus the emotion itself, "while creating and enhancing individual and group relationships" (Riggio et al., p. 65).

\section{INTELLIGENCE AND CULTURAL DIVERSITY}

The subjects of intelligence, workplace diversity and discrimination will continue to be topics of discussion for many years to come as human beings attempt to understand themselves, their fellow peers and uncover blatant and subtle forms of stereotypes. According to Alison Konrad (2006), in her book entitled Cases in Gender and Diversity in Organizations, workplace diversity discussions and reflections are at the center of heated debate across the globe (Karahalios, 2006). Professor Margaradia Karahalios, in her review of Konrad's book, states that "While the official rhetoric of organizations espouses diversity as one of its strategic goals, it has been very challenging to implement this goal in the daily functioning of organizations." In her book, Alison Konrad "helps us to understand the factors that confound diversity in the workplace and how these factors play out in daily business practices" (Karahalios, 2006). Specifically, she considers the role of demographics and work-related abilities and achievements in workplace discrimination, sexual harassment, work-life balance, organizational diversity programs, cross-cultural diversity, and entrepreneurship. Konrad considers some of the theory and research findings underlying each of these areas and then illustrates them using field-based business cases. The hope is that readers will understand that intelligence and cultural diversity, to a large extent, are products of environment and upbringing.

In the 1860s, Broca demonstrated a correlation between specific cognitive impairments and specific brain lesions. Then Galton developed a statistical method to rank the physical and intellectual powers and correlated them with one another, verifying a link between biology and professional accomplishment (Gardner, 1983). For centuries, research has been conducted in an attempt to distinguish individuals who are intelligent from those who are less intelligent (Valencia \& Suzuki, 2001). Since the emergence of the psychological testing movement launched in Europe and credited to Galton, and the development of cognitively based intelligence testing by U.S. psychologists Binet and Simon in 1905, has emerged contemporary research on intelligence extending beyond the conventional intelligence quotient (IQ) measures (Lussier \& Achua, 2001). There are a variety of paradigms in the field of human intelligence, where there are as many inquiries as there are answers on this topic (Sternberg \& Kaufman, 1998). Sternberg and Kaufman state that "These paradigms are largely complimentary rather than contradictory, looking at different aspects of and questions about intelligence" (1998, p. 497). 
Regardless of one's level of intelligence, people are likely to be victims of cultural conditioning, stereotypes and biased paradigms that exist in one's surroundings. As intelligent professionals who are aware of people's differences, we do need to avoid biased and sexist thinking and language in our vocabulary in the workplace. As a matter-of-fact, this continuous thinking can help us eliminate biases and stereotypes from our heads, hearts and eventually our habits. It is important to think differently using our heads (cognitive abilities and intelligences), feel differently through our hearts, and act differently thereby changing our daily habits. It all starts by thinking and acting in a bias-free manner. The suggestions, stated throughout the Workforce Diversity Management book (Mujtaba, 2007), provide diversity management ideas so professionals can be successful in achieving their stated outcomes synergistically. Many of the suggestions have been used by the authors as well as trainers, managers, educators, and leaders throughout the world to create a productive and happy work environment for all. As stated by Mahatma Gandhi, "Happiness is when what you think, what you say, and what you do are in harmony." The Workforce Diversity Management book is about creating harmony in one's head (thoughts), heart (feelings), and habits (behaviors) about people of diverse backgrounds and cultures. It is fair to say that diversity and culture-related issues are likely to, and should, impact a person's head, heart and habits if they are to lead to long-term peace and prosperity in life. Head implies continuous cognitive learning about each situation, thinking objectively based on current facts, awareness of universal principles, and knowledge generation. Heart implies the consistent controlling of one's feeling, basing it on objective facts, and aligning it with universal values. It means basing one's feeling for long-term impact, rather than short term satisfaction of personal desires that are linked to revenge, vengeance, payback, or retribution. Habits should be linked to one's objective feelings and universal principles. It means ensuring that one's day-to-day behaviors are aligned with one's universal principles of right and wrong, personal or professional values, and knowledge-based and goal-oriented feelings. Of course, the effective application of one's head, heart and habits require planning and the effective use of multiple intelligences which are within all human beings.

Harris and Moran (1996) offered a useful definition by suggesting, that "culture is a distinctly human capacity for adapting to circumstances and transmitting this coping skill and knowledge to subsequent generations" (p. 10). Earley and Ang (2003) had an interesting perspective on cultural intelligence. Early and Ang (2003) argued that "cultural intelligence refers to a person's capability to adapt effectively to new cultural contexts" (p. 59). Other theorists have expressed a socialization process that is an integral aspect of culture and cultural intelligence. "Different socialization practices [have emphasized] the development of modes of knowing that have relevance and value in a particular cultural context" (Riggio et al., p. 189). Thus, there are diverse views regarding what intelligence is globally across cultures. "Given these differences it is possible to be considered highly intelligent in one culture and intellectually lacking in another, based on the same skills or behaviors exhibited" (Riggio et al., 2002, p. 190).

Research findings indicated that differences between cultures in conceptions of intelligence reflect the various cultural groups' emphases on aspects of intelligence most valued (Valencia \& Suzuki, 2001). The difference may be attributed to the kinds of philosophies deeply rooted in each culture. The practices developed in one culture, society, or environment may not be considered intelligent or easily transferred to another culture, society, or environment (Earley \& Ang, 2003; Harris \& Moran, 1996). Not only may variations exist between cultures, within cultures, transmission of cultural meanings within a society may also be imperfect (Earley \& Ang). "Any two individuals from a common culture may hold slightly different meanings for the same event or construct, and these two individuals may have shared meanings with other parties in the society but not one another" (Earley \& Ang, p. 63). Since cultural differences may vary in skills and the ideal combination of cognitive processes within or between cultures, it is reasonable to expect that people from similar or different backgrounds may also differ in their problem solving approaches and in the patterns of skills acquired.

\section{Cultural And Social Intelligence}

The complexity of intelligence has existed for decades, with an ongoing debate among theorists as to the emphasis placed on cultural, environmental, and genetic factors (Valencia \& Suzuki, 2001). "The concept of human biological races is a construction socially and historically localized to $17^{\text {th }}$ and $18^{\text {th }}$ century European thought. Over time, different cultures have developed different sets (folk taxonomies) of socially defined races" (Fish, 2002, p. 8). The behaviors that are deemed as a significant aspect of intelligence vary from one culture to another or in some instances vary within the same culture. "Given this complexity, true adaptation, true cultural intelligence means a 
willingness to forgo the boxes, and to treat people as unique combinations of values, preferences, and needs" (Riggio et al., 2002, p. 199).

Genetic evidence rejects the misleading notion that there are distinct evolutionary lineages within humans, and clearly indicates that humans are a single species that share the majority of their genetic variations and adaptive traits (Fish, 2002). Furthermore, genetic evidence clearly indicates that biological races simply do not exist, and the genetic differences that do exist are explained primarily by geography and local adaptations. According to Fish, "Human physical appearance varies gradually around the planet, with the most geographically distant peoples generally appearing the most different from one another" (p. 8). Our world characterized by a hybridization of cultures, splitting or separating individuals into categorical boxes based on culture of origin may be ineffective, offensive, and genetically indefensible and biologically misleading (Fish, 2002; Riggio et al., 2002). Fish suggested:

We go on to explore the details of human biological variability and intelligence. It is a long way from the assertion that the Caucasoid, Mongoloid, and Negroid races differ in innate intelligence to the rather different scientific conclusion that the human species has no races, that there is no single form of intelligence, and that formal education helps people to develop a number of cognitive abilities (p. 27).

Perhaps the best promise of developing meaningful and positive leader-follower relations lies in understanding the modest levels of differentiation of each individual in all his or her complexity (Riggio et al., 2002). Rather than focusing on intelligence being based on ethnicity, gender or culture, it is more fruitful for leaders and researchers to study and understand the general theories of intelligence as they apply to all human beings.

Despite the differences in acquired or hereditary intelligence, and to become culturally competent individuals, all professionals should learn the skills of social intelligence. The book entitled "Social Intelligence: the New Science of Success," written by Karl Albrecht in 2006 and summarized by Dr. Raimi Abiodun in Workforce Diversity Management book (Mujtaba, 2007), discusses some basic tenets of human relations that should be practiced by each professional and manager in the workplace. Albrecht's (2006) goal is to help professionals, managers and leaders see the beauty in human behaviors and at the same time to let people understand those behaviors that differentiate effective leaders from ineffective ones. Effective leaders, according to Albrecht (2006), are those leaders who exhibit nurturing behaviors: behaviors that make people feel valued, capable, loved, respected, and appreciated. The book recognizes other forms of intelligence such as abstract intelligence, practical intelligence, emotional intelligence, aesthetic intelligence, and kinesthetic intelligence. Albrecht (2006) defines emotional intelligence as self-awareness and self-management, while social intelligence is defined as the way to deal with people. The idea is that one has to know the self first before one can improve the situation of others.

Professor Udechukwu (2006) states that the interesting and powerful thought about Albrecht's book is that it does not focus on teaching about different human traits or personalities, rather, and more practically, it focuses on the natural principles or fundamentals that partly lead to or form those individual traits and behaviors that are readily observable on either routine or continuous basis in various contexts. Another interesting observation of social intelligence is that at some level the concept ties into the theory of ethical behavior and leadership, which also advocates methods of dealing with individuals, groups, and organizational activities on a fair, consistent, and sound basis.

Professor Udechukwu concludes that the implication of social intelligence using S.P.A.C.E. is that executives and employees may be socially smarter about how their actions and behaviors shape their immediate and future life and work situations as well as the immediate and future life and work situations of their work subordinates and loved ones. According to Dr. Dr. Raimi Abiodun's review, the "S" factor represents situational awareness or the individual's situational radar and ability to understand and empathize with people in different situations (Abiodun, 2005). Situational awareness, similar to situational leadership skills, could be tied to a manager's ability to sense people's readiness to successfully complete as task as well as their feelings and intentions. Situational awareness includes the leader's belief in multiple ways to solve problems as well as the leader's belief that he or she is not self-centered. A self-centered individual will find cooperation by others difficult to accept; he or she will find it difficult to get people to accept him/her or share themselves with him/her. "P" stands for presence, or the way the leader affects others 
through his or her physical appearance, mood and demeanor, body language, and approachability. Albrecht states that leaders' behaviors must communicate a sense of confidence, professionalism, kindness, and friendliness to the followers. As a leader, one must pay special attention to the sense of presence he or she is communicating to others in order to be accepted and taken seriously. "A" stands for authenticity, which measures how honest and sincere a leader is both to him or herself and to the followers. Authenticity means a solid, trustworthy person with a positive attitude and an upstanding character. Finally, Dr. Raimi Abiodun states that the "C" in S.P.A.C.E. means clarity. Clarity is the leader's ability to make him or herself known and clear to his or her followers. Clarity measures your ability to express your thoughts, opinions, ideas, and intentions clearly to your audience or listeners. To influence other people with our ideas and thoughts, leaders must present the information in a way that makes it easy and fast for people to understand. Finally, "E" stands for empathy, which addresses how considerate the leader is to people's feelings. The leader must be able to show people that he or she can identify with and appreciate them for who they are. It is this sense of connectedness that establishes a condition of rapport between two people and inspires followers to cooperate with their leaders.

Effective interpersonal relationships are an important tool for quality leadership and productive organizations. Furthermore, developing a positive relationship with a diverse workforce could come from a corporate culture that institutes better corporate behaviors through education and training in the area of workforce diversity management.

\section{SUMMARY}

Studies do show that there are differences in how people of different cultures and genders see and approach various situations. People of various cultures and backgrounds have often been brought up with conditionings and nurturing behaviors that expect and reinforce certain aspect of intrapersonal, interpersonal and linguistic intelligences. Overall, the fact remains that, despite major cultural and economic differences, all people possess multiple intelligences in all economies and the best way to effectively manage this diversity is to gain more interpersonal skills regarding social and emotional intelligences, especially when living and working in a multicultural environment. This paper has attempted to provide a review of the major forms of intelligence with a focus on social and emotional skills that are needed for effective management and leadership in today's diverse workforce.

Regardless of one's upbringing and past conditioning, it is always helpful to clarify the facts, discuss the existing stereotypes, make clear the expectations of the company in the work environment, and provide a healthy learning environment for all. It is also helpful to create culturally competent individuals by expecting all professionals to become TRUE diversity champions (Mujtaba, 2007). Regardless of one's level of intelligence, through effective diversity training and management, managers and professional can become TRUE cross-cultural leaders that are able to work effectively in the context of cultural differences both nationally and internationally. Becoming a "TRUE" cross-cultural professional and diversity champion requires tolerating differences, respecting differences, understanding differences, and examining and exploring appropriate options.

Human beings have the power to change their attitudes to overcome ignorance, and to influence their offspring, peers and colleagues positively. It begins with a personal commitment to consciously and intelligently choose one's speech and thought patterns. Through their consciously acquired and natural levels of intelligence, culturally competent individuals and TRUE diversity champions create an inclusive work environment. These champions understand that the most intelligent individuals on earth respect human diversity and provide an avenue for all individuals to reach their full potential as per their dreams and capabilities. 


\section{BIBLIOGRAPHY}

1. Abiodun, Raimi (2007). Review of Social Intelligence: the New Science of Success in Workforce Diversity Management, by Bahaudin G. Mujtaba. Llumina Press. United States.

2. $\quad$ Albrecht, Karl (2006). Social Intelligence: the New Science of Success. Jossey-Bass.

3. Armstrong, T. (1999). Seven kinds of smart. New York: Plume \& Penguin Putnam, Inc.

4. $\quad$ Armor, D. J. (Ed.). (2003). Maximizing intelligence. New Brunswick, NJ: Transaction.

5. Blackburn, R. (Summer 2002). Multiple intelligences and leadership. Retrieved April 6, 2003, from ProQuest Database:

6. Bickman, L., \& Rogs, D. J. (1997). Handbook of applied social research methods. Thousand Oaks, CA: Sage.

7. Brualdi, A. C. (1996). Multiple intelligences: Gardner's theory. Retrieved December 16, 2002, from ERIC Clearinghouse on Assessment and Evaluation Washington DC Database:

8. Crainer, S., \& Dearlove, D. (1999). Death of executive talent [electronic version]. Journal of Management Review, 88 (7), 16-23 July. Retrieved July 29, 2003, from http//rdsweb2.rdsinc.com/

9. $\quad$ Creswell, J. W. (1994). Research design. Thousand Oaks, CA: Sage.

10. Dessler, G. (2001). Management: Leading people and organizations in the $21^{\text {st }}$ century. (2 ${ }^{\text {nd }}$ ed.). Upper Saddle River, NJ: Prentice Hall.

11. Devlin, S., Jones P, \& Martin D. (2002). Intelligence and success: is it all in the genes? Mahwah, NJ: Lawrence Erlbaum.

12. Earley, P. C., \& Ang S. (2003). Cultural intelligence: Individual interactions across cultures. Stanford, CA: Stanford University Press.

13. Ellis, K. (2003). Making waves: with a leadership crisis on the horizon, organizations are looking within to build talent pools of their own [electronic version]. Journal of Training, 40(6), 16, June. Retrieved July 29, Retrieved July 29, 2003, from http://rdsweb2.rdsinc.com/

14. Esters, I. G., \& Ittenbach, R. F. (1999, June). Contemporary theories and assessments of intelligence: A primer. Retrieved October 20, 2003, from EBSCO Database:

15. Eysenck, H.J. (1998). A new look intelligence. New Brunswick, NJ: Transactions Publishers.

16. Fiedler, F. E. (2001). When IQ + experience = performance [electronic version]. Journal of Leadership and Organizational Development, 22 (3), 132.

17. Fish, J. M. (2002). Race and intelligence: Separating science from myth. Mahwah, NJ: Lawrence Erlbaum Associates.

18. Freeman, L. (1999, September). When the boss is the problem. Credit Union Journal, 3 (36), 18, 33 September. Retrieved July 29, 2003, from: http// rdsweb2.rdsinc.com/texis/rds/suite/ +smeBljzCwwwww Fqzvh+s+svwwxFqdlprdnD

19. Gall, M. D., Gall, J. P.,\& Borg, W. R. (Eds.). (2003). Educational research: An introduction (7 $7^{\text {th }}$ ed.). New York: Pearson Education Inc.

20. Gall, M. D., Gall, J. P., \& Borg, W. R. (Eds.). (1996). Educational research: An introduction (4 ${ }^{\text {th }}$ ed.). New York: Pearson Education Inc.

21. Gardner, H. (1991). The unschooled mind: How children think and how schools should teach. New York: BasicBooks.

22. Gardner, H. (1993). Multiple intelligences: The theory in practice. New York: BasicBooks.

23. Gardner, H. (1983). Frames of Mind. New York: BasicBooks.

24. Gardner, H. (1995, September 15). A cognitive view of leadership. Retrieved April 6, 2003, from EBSCO Web Site: http://web15.epnet.com/citation.asp?tb=1\& ug=dbs+0\%2C1\%2C2\%2C3\%2C5+In+en\%2D

25. Gardner, H. (1999). Intelligence reframed. New York, NY: BasicBooks.

26. Hesselbein, F., Goldsmith, M., \& Beckhard, R. (1996). The leader of the future: New visions, strategies, and practices for the next era. $\left(1^{\text {st }}\right.$ ed.). San Francisco, CA: Jossey-Bass.

27. Karahalios, Margarida (2006). Review of Alison Konrad's book entitled Cases in Gender and Diversity in Organizations. SAGE Publications. Journal of Applied Management and Entrepreneurship, Vol. 11, Num. 3; Pages 100-101.

28. Kline, P. \& Saunders, B. (1998). Ten steps to a learning organization ( $2^{\text {nd }}$ ed.). Arlington, VA: Great Ocean Publishers. 
29. Konrad, Alison M. (2006). Cases in Gender and Diversity in Organizations. SAGE Publications.

30. Lebhar-Friedman, Inc. (2003). Recruiting execs learn economics of retention at annual conference [Electronic Version]. Journal of Nation's Restaurant News, 37 (27): 18, July. Retrieved July 29, 2003 from http//rdsweb2.rdsinc.com/.

31. Locke, L.F., Silverman, S.J., \& Spirduso, W.W. (1998). Reading and understanding research. Thousand Oaks, CA: Sage.

32. Mujtaba, B. G. (2007). Workpalce Diversity Management: Challenges, Competencies and Strategies. ISBN: 1-59526-548-1. Llumina Press; website: http://www.llumina.com/store/workforcediversitymanagement.htm.

33. Mujtaba, B. (2006). Cross Cultural Change Management. ISBN: 1-59526-568-6. Llumina Press, Tamarac, Florida. Website: www.Llumina.com

34. Project Summit. (2002, December 16). Howard gardner: Multiple intelligence theory proponent. Retrieved December 16, 2002, from http://www.aenc.org/ABOUT/MI-Gardner.html.

35. Riggio, R.E., Murphy, S.E. \& Pirozzolo, F. (2002). Multiple intelligences and leadership. Mahwah, NJ: Lawrence Erlbaum Associates, Inc.

36. Robbins, S. P. (2001). Organizational Behavior (9th ed.). Upper Ruzgis, P. \& Grigorenko E.L. (1994). Cultural meaning systems, intelligence and personality. New York, NY: Cambridge University Press. Saddle River, NJ: Prentice Hall.

37. Samuda, R.J. (1998). Psychological testing of American minorities: Issues and consequences. (2 ${ }^{\text {nd }}$ ed.). Thousand Oaks, CA. Sage Publications.

38. Shahnasarian, M. (1996). Self-Directed search in business and industry. Odesssa, FL: Psychological Assessment Resources.

39. Sternberg, R. J. (2003). Wisdom, intelligence, and creativity synthesized. New York: Cambridge University Press.

40. Sternberg, R.J., Grigorenko, E.L. (2003). The psychology of abilities, competencies, and expertise. New York: Cambridge University Press.

41. Sternberg, R.J., \& Kaufman, J.C. (2001). The evolution of intelligence. Mahwah, NJ: Lawrence Erlbaum Associates, Publishers.

42. Tyrell, B. \& Swain, B. (2000). The right stuff [electronic version]. Journal of Pharmaceutical Executive, 20 (8), 86-94. Retrieved July 29, 2003, from http://rdsweb2.rdsinc.com/texis/rds/suite/+smeBljzCwwwwwFqzvh+s+svwwxFqdlprdnD.

43. Udechukwu, Ikwukananne I. (2006). Review of Karl Albrecht's book entitled Social Intelligence: the New Science of Success. Jossey-Bass. Journal of Applied Management and Entrepreneurship, Vol. 11, Num. 3; Pages 97-99.

44. Welch, K. C. (2002). The bell curve and the politics of negrophobia. Mahwah, NJ: Lawrence Erlbaum Associates.

45. White, S. H. (2000). Conceptual Foundations of IQ Testing. Psychology, Public Policy and Law, 6(1), 33-43.

46. Wilson, S. D., (2005). The relationship between leadership and domains of multiple intelligences. UMI Microform Num: 3151206. ProQuest Information and Learning Company.

47. Yang, S. Y. \& Sternberg, R. J. (1997). Conceptions of intelligence in ancient Chinese philosophy. Journal Theories of Philosophical Psychology, 7 (2) 57-69. 


\section{NOTES}

